\title{
Review
}

\section{Monitoring the health-related labelling of foods and non-alcoholic beverages in retail settings}

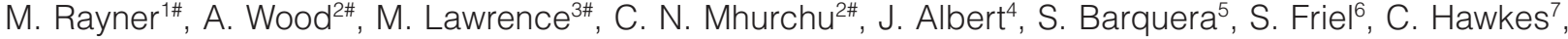 \\ B. Kelly ${ }^{8}$, S. Kumanyika ${ }^{9}$, M. L'Abbé ${ }^{10}$, A. Lee ${ }^{11}$, T. Lobstein $^{12,13}$, J. Ma ${ }^{14}$, J. Macmullan ${ }^{15}$, S. Mohan ${ }^{16}$, \\ C. Monteiro ${ }^{17}$, B. Neal ${ }^{18}$, G. Sacks ${ }^{3}$, D. Sanders ${ }^{19}$, W. Snowdon ${ }^{3,20}$, B. Swinburn ${ }^{2,3}$, S. Vandevijvere ${ }^{2}$ and \\ C. Walker ${ }^{21}$ for INFORMAS^
}

\begin{abstract}
${ }^{1}$ British Heart Foundation Health Promotion Research Group, University of Oxford, Oxford, UK; ${ }^{2}$ School of Population Health, University of Auckland, Auckland, New Zealand; ${ }^{3}$ WHO Collaborating Centre for Obesity Prevention, Deakin University, Melbourne, Victoria, Australia; ${ }^{4}$ Food and Agriculture Organization (FAO), Rome, Italy; ${ }^{5}$ National Institute of Public Health, Mexico City, Mexico; ${ }^{6}$ National Centre for Epidemiology and Public Health, Australian National University, Canberra, Australia; ${ }^{7}$ World Cancer Research Fund International, London, UK; ${ }^{8}$ School of Health and Society, University of Wollongong, Wollongong, New South Wales, Australia; ${ }^{9}$ Perelman School of Medicine, University of Pennsylvania, Philadelphia, Pennsylvania, USA; ${ }^{10}$ Department of Nutritional Sciences, University of Toronto, Toronto, Canada; ${ }^{11}$ School of Public Health and Social Work and School of Exercise and Nutrition Sciences, Queensland University of Technology, Brisbane, Australia; ${ }^{12}$ International Association for the Study of Obesity, London, UK; ${ }^{13}$ Public Health Advocacy Institute of Western Australia, Curtin University, Perth, Australia;

${ }^{14}$ Chinese Center for Disease Control and Prevention (CCDC), Beijing, China; ${ }^{15}$ Consumers International, London, UK; ${ }^{16}$ Public Health Foundation of India, New Delhi, India;

${ }^{17}$ School of Public Health, University of Sao Paulo, Sao Paulo, Brazil; ${ }^{18}$ The George Institute for Global Health, Sydney, Australia; ${ }^{19}$ School of Public Health, University of the Western Cape, Cape Town, South Africa; ${ }^{20} \mathrm{Pacific}$ Research Centre for the Prevention of Obesity and Non-communicable Diseases (C-POND), Suva, Fiji; ${ }^{21} \mathrm{Global}$ Alliance for Improved Nutrition (GAIN), Geneva, Switzerland
\end{abstract}

\begin{abstract}
Summary
Food labelling on food packaging has the potential to have both positive and negative effects on diets. Monitoring different aspects of food labelling would help to identify priority policy options to help people make healthier food choices. A taxonomy of the elements of health-related food labelling is proposed. A systematic review of studies that assessed the nature and extent of health-related food labelling has been conducted to identify approaches to monitoring food labelling. A step-wise approach has been developed for independently assessing the nature and extent of health-related food labelling in different countries and over time. Procedures for sampling the food supply, and collecting and analysing data are proposed, as well as quantifiable measurement indicators and benchmarks for health-related food labelling.
\end{abstract}

Keywords: Food environments, food labelling, INFORMAS, monitoring.

obesity reviews (2013) 14 (Suppl. 1), 70-81

Address for correspondence: M Rayner, Nuffield Department of Population Health, British Heart Foundation Health Promotion Research Group, University of Oxford, Oxford OX3 7LF, UK.

E-mail: mike.rayner@dph.ox.ac.uk

\footnotetext{
\#Members of the writing group for this manuscript, listed in order of their contribution to the writing of the manuscript.

AINFORMAS is the International Network for Food and Obesity/non-communicable diseases Research, Monitoring and Action Support. All authors who are not members of the writing group are listed in alphabetical order, and contributed to discussion of the key concepts and issues raised in this manuscript as part of the first formal meeting of INFORMAS from 19 to 23 November 2012.
} 


\section{Background}

The rising burden of obesity and diet-related noncommunicable diseases (NCDs) has focused attention on policy-responsive aspects of the food environment that might influence consumer behaviours towards the selection of healthy food choices and/or influence food manufacturers towards improving the healthiness of their food products. Food labelling is a policy area where improvements have potential health benefits.

The Codex Alimentarius Commission (Codex) defines food labelling as 'any written, printed or graphic matter that is present on the label, accompanies the food, or is displayed near the food, including that for the purpose of promoting its sale or disposal' (1). Most elements of food labelling are voluntary on the part of the food producer or retailer, but in many jurisdictions, some elements are mandatory (such as lists of ingredients) and others are subject to mandatory conditions (such as nutrient claims).

Food labels are an important source of useful information for consumers aiming to improve their health depending on the labelling content, its format and context (2-9). Content is obviously important: for example, labelling is only as useful in as much as it is truthful. Also, some labelling formats are clearly more useful than others. For example, for lists of ingredients, quantitative ingredient declarations (QUID) are more informative than lists in order of weight, and for front-of-pack supplementary nutrition information, formats that interpret the information for the consumer, using say colour coding, are more understandable than those that merely use numbers. Finally, the context in which labelling is provided is also important to its utility. For example, food labelling will only be useful if the consumer trusts the information.

Food labels, as well as being a source of information, are also a source of marketing claims by food producers. Such claims have the potential to inform consumers, but can also mislead consumers in their food choices by, for example, highlighting positive product attributes while ignoring other, less desirable characteristics $(4,10)$.

There are many components of food labelling, some more pertinent to health than others. For example, consumers may use country of origin labelling to make purchasing decisions, but such decisions may not impact on the nutritional quality of the food consumed. This paper focuses only on health-related food labelling, i.e. lists of ingredients, nutrient declarations, supplementary nutrition information, nutrition claims and health claims (for definitions see the glossary).

Food labelling is increasingly found in a variety of different venues including food retail outlets, quick service/ fast food and other types of restaurants, and school and workplace cafeterias. Increasingly, electronic media are used to provide food labelling information and claims.
There appears to have been an increase in the prevalence of some types of health-related food labelling in recent years, particularly front-of-pack supplementary nutrition information (5).

With the increase in labelling venues and in the types of labelling, such as supplementary nutrition information, comes the challenge of regulating an ever-expanding food labelling environment. In 2010, Codex published the eighth edition of its General Standards for the Labelling of Prepackaged Foods (1), and in 2012 amended its Guidelines on Nutrition Labelling (11) and its Guidelines for Use of Nutrition and Health Claims (12). Several countries and jurisdictions, such as the United States and the European Union, have developed labelling regulations that are consistent with Codex's standards and guidelines. An overview of international and national regulations on health-related food labelling has been published by the World Health Organization (WHO) (10), but is now quite out of date (13).

The International Network for Food and Obesity/NCD Research, Monitoring and Action Support (INFORMAS) is a global network of public-interest organizations and researchers that aims to monitor, benchmark and support public and private sector actions to create healthy food environments and reduce obesity, NCDs and their related inequalities (14). The food labelling module of INFORMAS seeks to monitor food labelling globally, and aims to answer the research question, 'What health-related labelling is present for foods and non-alcoholic beverages (henceforth just "foods")?" This paper focuses on the monitoring of health-related food labelling on food packages in retail settings as part of the food labelling module of INFORMAS. (For a definition of a 'retail setting' see the INFORMAS module on monitoring the retail environment (15)).

The monitoring of health-related food labelling in quickservice/fast food restaurants and other food service environments is not addressed in this paper. Other types of in-store health-related information other than that on food packaging (e.g. shelf tags, posters near foods) in retail settings are also not considered.

The purposes of this paper were (i) to provide a taxonomy of food labelling components; (ii) to review previous and current activities to measure and report food labelling; (iii) to propose a step-wise approach to monitoring food labelling and (iv) to propose measurement indicators and benchmarks for providing useful health-related food labelling on food packaging within the retail sector.

\section{Scope, definitions and taxonomies}

In order to define more precisely the focus of this module, a review of taxonomies for food labelling components for foods was carried out by reviewing guidelines from international governing bodies and legislative documents. Because Codex is the most authoritative international body 
concerned with food labelling, the taxonomy used for this module was based on the taxonomy implicit within Codex food labelling standards and guidelines (henceforth 'standards') and that the definition of terms used in the taxonomy should, wherever possible, be as given by Codex. The proposed taxonomy is shown in Fig. 1 and the definitions of terms used in this taxonomy can be found in the glossary.

Note that our taxonomy takes no account of whether the labelling is verbal, numerical or pictorial (symbolic), e.g. 'high in whole grain', ' $10 \%$ whole grain' and a symbol representing whole grain present would all be defined as a health-related ingredient claim according to the taxonomy presented in Fig. 1. Nor does the taxonomy take any account of whether the labelling is mandatory or voluntary.

Note also that a number of fairly subjective judgements will need to be made to classify actual labelling according to this taxonomy. For example, 'diet' in some countries is an implied nutrient content claim meaning 'low calorie'; whereas, in other countries 'diet' is an implied general health claim meaning 'healthy'.

The use of Codex standards to develop this taxonomy leads to three problems because of:

1. Some anomalies within Codex standards, e.g. Codex defines a nutrient function claim as a type of nutrition claim whereas it would be more logical to consider it as a type of health claim. The list of Codex definitions used as the basis for this module has therefore been modified (as indicated) to provide greater clarity to our taxonomy.

2. A lack of Codex definitions for some labelling subcomponents, e.g. of supplementary nutrition information. This has been addressed by adopting additional definitions (and thereby creating additional labelling subcomponents not found in Codex standards) on the basis of national or international legislation and relevant government reports. For example the definitions of the U.S. Institute of Medicine (5) have been used as a starting point for subdividing supplementary nutrition information.

3. Ambiguities in Codex definitions leading to difficulties in assessing:

(i) How claims relating to the content of some ingredients, such as whole grain, should be categorized. Here, such claims are classified as nutrition claims because, although they do not refer to nutrients, they do refer to an ingredient as if it has the functions of a nutrient. This has been addressed by the creation of an additional component not found in Codex standards called 'healthrelated ingredient claims';

(ii) How imprecise health-related claims, such as 'healthy', should be categorized. This has been addressed by the creation of an additional component not found in Codex standards called 'general health claims' to cover such claims. On the other hand, when health-related claims clearly imply a connection to a particular nutri- ent, ingredient or health condition, they should be classified as a nutrient claim, a health-related ingredient claim, a nutrient and other function claim, or a reduction of disease risk claim depending on the implied connection. For example, if a heart-shaped symbol seems to imply a relationship between consumption of the product and cardiovascular disease risk, then it should be categorized as a disease risk reduction claim.

The scope of this module does not extend to monitoring the scientific accuracy of labelling. For instance this module does not provide guidance on monitoring whether a nutrient declaration on a food label is accurate, or whether a health claim is substantiated. Nevertheless, the monitoring data collected using the framework could be used in conjunction with legal standards to assess, to some extent at least, whether labelling is legal or not.

\section{Review of previous food labelling studies and monitoring activities}

A systematic review was conducted to identify previous studies that assessed and reported the presence of healthrelated food labelling in retail outlets providing mainly packaged foods. The review included studies that assessed the presence of at least one of the following food-labelling components: supplementary nutrition information, nutrition claims and health claims. Studies of the presence of nutrient declarations alone were not included because their focus was normally the nutrient composition of foods rather than its labelling. The results reported here form part of a more comprehensive systematic review, the results of which will be reported in detail elsewhere.

Six databases (PubMed, Science Direct, ProQuest, Web of Science, Oxford Journals Online, Google Scholar) were searched using combinations of the MeSH terms 'food label"', 'nutrition policy', 'food packaging', 'health promotion' and the keywords 'health claim', 'health information', 'nutrition claim', 'nutrition information', 'survey' and 'study'. Studies before 1990 were excluded. Only studies in supermarkets and similar retail outlets were included (i.e. studies of labelling in such venues as quick service restaurants, schools or workplaces were excluded). In addition to peer-reviewed journals, publicly available government reports were included in the search. Only research reported in English was included.

Among studies of labelling of foods sold in retail outlets, 15 were identified as regional studies (16-30), three were identified as national studies (31-36) and five included multiple countries (37-41). Four of these studies were part of ongoing surveys or monitoring and surveillance systems (16,31-35,37), and a further seven were studies repeated over a finite time period $(17,18,21,22,24,25,27)$. Research outputs from ongoing studies are counted as one study. 


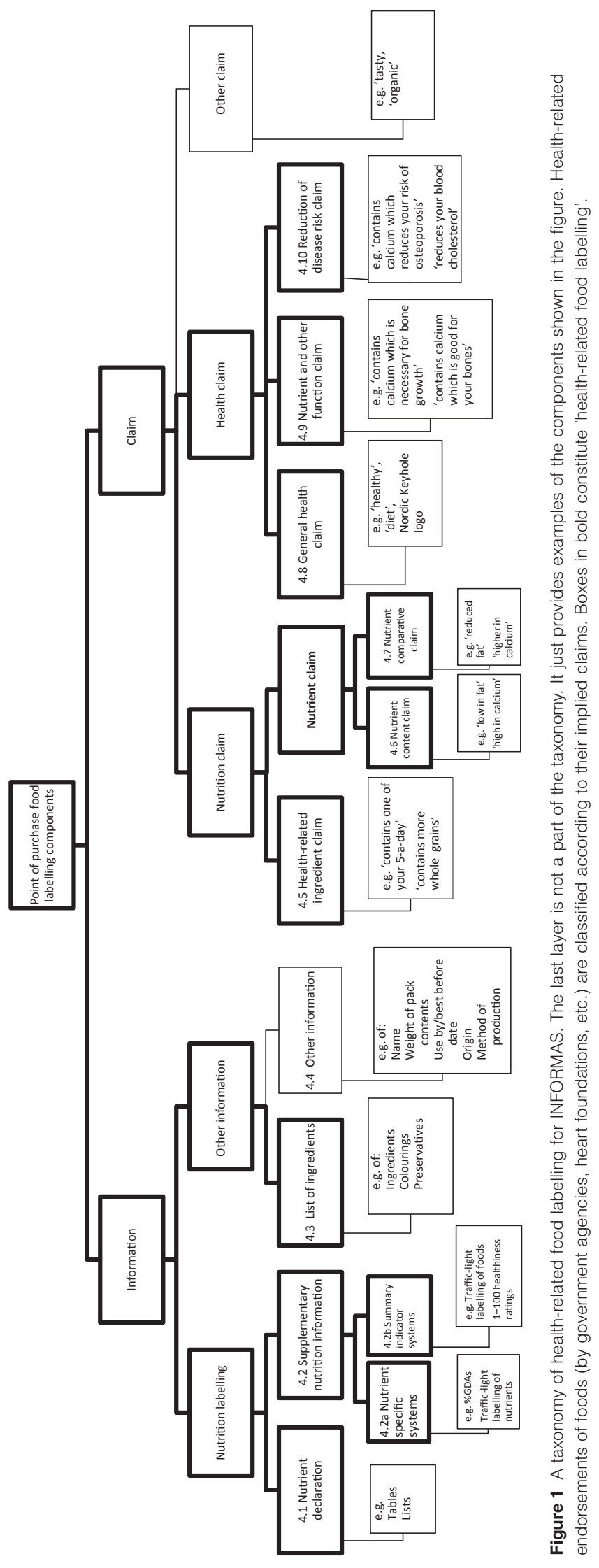




\section{Approaches to sampling and data collection}

The sampling frame and methods of data collection methods varied among the studies. While most studies surveyed selected foods or food categories sold in selected retail outlets, mainly supermarkets, there was a study that surveyed all packaged food products sold in retail outlets across the survey area (19).

In most studies, data were collected in-store (17-25,27$30,38-40)$ and recorded on survey forms completed by the research team. However, several of the large-scale studies purchased the products from stores or had the products or product information delivered to the research premises for analysis $(16,31-35,37,41)$. Other studies utilized websites to collect label information $(36,39,40)$. In one study, agreements were signed with the food industry and food retailers to allow product information to be sourced directly from the food manufacturers, and to allow data collectors to photograph the products in store $(33,35)$.

In addition to collecting information about supplementary nutrition information, nutrition claims or health claims, most of these studies collected information about the manufacturer $(20,28-30,38,41)$, ingredient content (21,31-34), nutrient content $(19,21-24,27,29-36,39,40)$ and declared serving size $(17,19,30,31,33,41)$.

The granularity of data collection varied, with some studies recording the presence or absence of information or claims, and other studies collecting more detailed data such as the reference nutrient for the claims or even their precise wording (e.g. 20,28,29).

\section{Monitoring objectives and measurement parameters}

A common objective of all these labelling studies was to determine the prevalence of health-related food labelling components at a particular point in time. Additional study findings were dependent on the study design and data granularity. For example, ongoing studies such as the U.S. Food and Drug Administration's (FDA) Food Label and Package Survey (FLAPS) or the Food Standards Australia New Zealand Ongoing Food Label Monitoring Survey have allowed for comparisons to be made over time $(31,32,34,37)$. Studies with a higher level of data granularity reported findings such as the prevalence of specific health and nutrition claims (e.g. nutrient claims for transfat) (e.g. 19,29,31,34), or the format for supplementary nutrition information (38).

\section{Measurement limitations and opportunities for improvement}

A number of limitations were identified by the authors of these studies. The most common limitation was the small sample size of either foods or retail outlets surveyed because of limited resources. Other limitations included sample selection biases because of seasonal availability, position of the food in the store or on-shelf, the location of the retail store, or the omission of some types of food such as store-owned brands $(20,28,32,34,37,38)$. In addition, authors of the studies thought that the categorization of food label components could have been affected by an interpretation bias $(19,37)$, related to the subjectivity in classifying labelling components.

Despite these limitations, studies such as the U.S. FDA FLAPS survey $(31,32,34)$ or the French Oqali database $(33,35)$ collect regular information from a wide range of food products and food retailers. Smaller-scale surveys have also been able to survey a large number of food labels, despite a limited sample of retail outlets (e.g. 17-19).

\section{Proposed approach to the prioritisation of activities to monitor food labelling}

The philosophy of INFORMAS is that each country should choose an appropriate set of monitoring activities based on the resources available and local priorities (14). Although monitoring will most likely vary in the way retail outlets and foods are sampled, and in the granularity of the data collected, all countries should use standard protocols that can be repeated over time and should aim to collect a minimum set of data so that the labelling environments in different jurisdictions can be compared.

As well as taking account of the resources available, it is proposed that monitoring activities should consider the relative importance of different food labelling components, the information conveyed through those components, the format of those components in relation to their likelihood in affecting health-related food choices and some aspects of the context in which the labelling is presented. In the section later, methods for prioritizing particular aspects of labelling and their contexts are explained, but first methods for sampling retail outlets and foods are discussed.

\section{Proposed procedures for sampling retail outlets and foods}

The proposed step-wise approach to sampling retail outlets and foods is shown in Table 1.

First, the types and numbers of retail outlets from which labelling data are going to be collected needs to be determined. The major retail outlets (in terms of numbers of foods sold there, \% market share, etc.) would seem an obvious place to start. Ideally, the sample of outlets should be selected randomly, with the size of the sample dependent on the precise research questions, e.g. whether it is considered necessary to ascertain the prevalence of rare labelling components by food category. 
Table 1 Step-wise approach to selection of retail outlets and foods surveyed

\begin{tabular}{|c|c|c|c|}
\hline Monitoring aspect & 'Minimal' monitoring & 'Expanded' monitoring & 'Optimal' monitoring \\
\hline Selection of retail outlets & $\begin{array}{l}\text { From one or more selected retail } \\
\text { outlets }\end{array}$ & $\begin{array}{l}\text { From all retail outlets of a particular type } \\
\text { (e.g. retail outlets of a particular size) in } \\
\text { the jurisdiction }\end{array}$ & $\begin{array}{l}\text { From all retail outlets in } \\
\text { the jurisdiction }\end{array}$ \\
\hline Selection of foods & $\begin{array}{l}\text { From all foods in selected categories } \\
\text { of pre-packaged foods }\end{array}$ & From all pre-packaged foods & From all foods \\
\hline
\end{tabular}

Next, procedures for sampling foods within outlets need to be decided and justified. At an early stage it needs to be decided whether monitoring will just include packaged foods or unpackaged foods as well. If unpackaged foods are not included then many healthy foods, such as fruit and vegetables, will be missed, meaning that the sample is likely to be less healthy than all the foods supplied in retail outlets.

For the monitoring data to be reflective of the food labelling environment, the data should be as representative as possible. Ideally, the sample frame (denominator) should be all foods available/sold in the country (or other geographical region under consideration), but it could, for example, be all foods of a particular type or category, all foods sold by just one retailing company, all foods of a particular category sold by one retailing company, etc.

The sample of foods should be drawn from the sample frame of foods by a random selection process, e.g. using a stock list provided by the store. The sample size (numerator) needs to be calculated using standard powercalculations and it may not need to be very large, if the sample frame (denominator) is relatively constrained.

In collecting data on the extent and nature of food labelling it will clearly be necessary to examine individual food packets. There are three basic methods of collecting food labelling data from food packaging:

1. Purchasing the products for extracting food labelling information later

2. Photographing the food packet (preferably all sides)

3. Recording food labelling information in store using a data collection form

If methods 2 and 3 are selected then permission from the store to collect data may need to be sought. Note that methods 1 and 2 make extracting data from food packaging considerably easier and more reliable, and may not require significantly more resources than method 3 .

\section{The relative importance of different food labelling components}

Systematic reviews of consumer understanding and use of food labelling (2-9) were analysed to determine the relative importance of labelling components when making healthrelated choices about foods. From these reviews, we have concluded that monitoring of health-related food labelling in relation to NCDs (the focus of INFORMAS) should involve the recording of the presence/absence and other aspects of the lists of ingredients, nutrient declarations, supplementary nutrition information, nutrition claims and health claims, but not other non-health-related labelling information (e.g. date marking, country of origin), and non-health-related claims (e.g. relating to environmental sustainability, such as 'organic', or those relating to taste such as 'chocolaty').

\section{The relative importance of the information conveyed through different food labelling components}

The content of food labelling has an important bearing upon its utility. The focus of INFORMAS is the prevention of obesity and NCDs, but some health-related food labelling is only relevant to diseases and health conditions unrelated to NCDs (such as micronutrient deficiencies). Here, it is proposed that for health claims the 'minimal' level of monitoring should be of claims that refer to NCDs or health conditions related to NCDs (such as obesity). Expanded monitoring should involve health claims in relation to other health conditions and diseases. Similarly, for nutrition information and nutrition claims, it is proposed that 'minimal' monitoring should be for labelling of nutrients and ingredients relevant to NCD prevention. 'Expanded' monitoring should involve nutrition claims and nutrition information that are relevant to other diseases and health conditions.

There are various possible ways of prioritizing nutrients relevant to NCD prevention. The WHO has developed a list of population dietary goals, that, if attained, would lead to a significant reduction in the burden of NCDs (42). These goals relate to total fat, saturated fat, polyunsaturated fat, n-6 polyunsaturated fatty acids, n-3 polyunsaturated fatty acids, trans-fats, monounsaturated fat, total carbohydrate, free (added) sugars, protein, cholesterol, sodium, dietary fibre and non-starch polysaccharides. 
Table 2 Codex, World Health Organization (WHO), and International Network for Food and Obesity/non-communicable diseases Research, Monitoring and Action Support (INFORMAS) lists of prioritised nutrients and other food components

\begin{tabular}{|c|c|c|c|}
\hline $\begin{array}{l}\text { Codex recommends as a } \\
\text { minimum for nutrient } \\
\text { declarations (11) }\end{array}$ & WHO population goals (42) & $\begin{array}{l}\text { INFORMAS food labelling } \\
\text { monitoring: 'minimal' } \\
\text { monitoring }\end{array}$ & $\begin{array}{l}\text { INFORMAS food labelling } \\
\text { monitoring: 'expanded' } \\
\text { monitoring }\end{array}$ \\
\hline Energy & & Energy & \\
\hline Total fat & Total fat & Total fat & Polyunsaturated fat \\
\hline Saturated fat & Saturated fat & Saturated fat, & n-6 polyunsaturated fatty acids \\
\hline Trans-fats (in countries where & Polyunsaturated fat & Trans-fats & n-3 polyunsaturated fatty acids \\
\hline it is a public health concern) & n-6 polyunsaturated fatty acids & Protein & Monounsaturated fat \\
\hline Protein & n-3 polyunsaturated fatty acids & Total carbohydrate & Cholesterol \\
\hline Total carbohydrate & Trans-fats & Total sugars & Dietary fibre \\
\hline Total sugars & Monounsaturated fat & Free sugars & Non-starch polysaccharides \\
\hline \multirow[t]{7}{*}{ Sodium } & Total carbohydrate & Sodium & \\
\hline & Free sugars & & \\
\hline & Protein & & \\
\hline & Sodium & & \\
\hline & Dietary fibre & & \\
\hline & Non-starch polysaccharides. & & \\
\hline & Fruit and vegetables & Fruit and vegetables & \\
\hline
\end{tabular}

Those dietary components listed in bold are those shared by the Codex and WHO lists.

However, here it is proposed that 'minimal' monitoring should be of labelling (both nutrition labelling and nutrition claims) that refers to those nutrients that are recommended by Codex for mandatory declaration within nutrient declarations (11). These nutrients are energy, protein, available carbohydrate (i.e. total carbohydrate excluding fibre), total sugars, fat, saturated fat and sodium (or the amount of sodium in salt equivalents as 'salt'). Some of these nutrients are more relevant to NCD prevention than others, but for completeness, it is recommended that, at minimum, monitoring should collect information relating to all seven nutrients.

Codex notes that 'the amount of trans-fatty acid may be required [for nutrient declaration] according to national legislation' (11) so it is also recommended that trans-fats should be a priority nutrient. In addition, recognizing (as does WHO in setting dietary goals (42)) that it is free sugars, not total sugars, that are most closely related to health, then it is also recommended that free sugars should be considered a priority nutrient in relation to the monitoring of food labelling while recognizing that it is total sugars, not free sugars, to which most labelling refers.

Other nutrients such as polyunsaturated fatty acids, fibre, minerals and vitamins do play a role in the maintenance and promotion of health and yet are not so critical in causing or protecting against NCDs. 'Expanded' monitoring should collect labelling data in relation to non-priority nutrients.

As well as goals for nutrient intakes, WHO proposes a goal for the intake of some foods and, in particular, for fruit and vegetables. Accordingly, it is proposed that 'minimal' monitoring should involve the collection of information about labelling that relates to fruit and vegetable content (the most common type of fruit and vegetable labelling is a health-related ingredient claim).

Prioritisation of nutrients for monitoring labelling by INFORMAS is summarized in Table 2.

\section{The relative importance of the format of the food labelling component}

The format for food labelling information has an important bearing upon its utility, and the format of a food labelling claim is important in relation to its effects on food purchasing. Some aspects of format are relatively easy to define; while others are less easy. For instance, the presence or absence of traffic-light colours in supplementary nutrition information is relatively easy to score (and this should be part of 'minimal' monitoring), but the various wordings of some types of health and nutrition claims are difficult to classify and should be attempted only in well-resourced (expanded monitoring) projects. Even the positioning of some labelling components such as supplementary nutrition information can be an important determinant of its use, so monitoring positioning would be desirable.

\section{The context in which the labelling is presented}

The context for food labelling is an important determinant of its utility and use. Accordingly, a global monitoring framework for food labelling needs to take account of differences in regulatory environments and in private- and public-sector policies and actions that promote or impede 
Table 3 Step-wise approach to data collection

\begin{tabular}{|c|c|c|c|}
\hline Food labelling component & 'Minimal' monitoring & 'Expanded' monitoring & 'Optimal' monitoring \\
\hline Product information & $\begin{array}{l}\text { Product name } \\
\text { Product composition data for priority } \\
\text { nutrients } \\
\text { Recommended serving size }\end{array}$ & $\begin{array}{l}\text { Manufacturer information } \\
\text { Product composition data for non-priority } \\
\text { nutrients } \\
\text { Price }\end{array}$ & \\
\hline Lists of ingredients & $\begin{array}{l}\text { Presence or absence } \\
\text { Presence or absence of QUID for priority } \\
\text { ingredients (fruit or vegetable) }\end{array}$ & $\begin{array}{l}\text { Whether QUID for: all, most or } \\
\text { characterizing* ingredient(s), }\end{array}$ & \\
\hline Nutrient declarations & $\begin{array}{l}\text { Presence or absence } \\
\text { Presence of declarations for priority } \\
\text { nutrients }\end{array}$ & $\begin{array}{l}\text { Format (whether list or table, whether \% } \\
\text { reference intakes, etc.) } \\
\text { Presence of declarations for non-priority } \\
\text { nutrients }\end{array}$ & \\
\hline $\begin{array}{l}\text { Supplementary nutrition } \\
\text { information by: } \\
\text { Nutrient specific systems } \\
\text { Summary indicator systems }\end{array}$ & $\begin{array}{l}\text { Presence or absence } \\
\text { Format (whether \% reference intakes, } \\
\text { traffic-light colours, stars etc) } \\
\text { Presence of declarations for priority } \\
\text { nutrients }^{\dagger}\end{array}$ & $\begin{array}{l}\text { Presence of declarations for non-priority } \\
\text { nutrients }^{\dagger} \\
\text { Reference quantity(s) for declarations }{ }^{\dagger}\end{array}$ & $\begin{array}{l}\text { Position on } \\
\text { packaging }\end{array}$ \\
\hline $\begin{array}{l}\text { Nutrition claims by: } \\
\text { Health-related ingredient claims } \\
\text { Nutrient content claims } \\
\text { Nutrient comparison claims }\end{array}$ & $\begin{array}{l}\text { Presence of claims for priority nutrients } \\
\text { or ingredients }\end{array}$ & $\begin{array}{l}\text { Presence of claims for non-priority nutrients } \\
\text { Format of claims (whether verbal, numerical, } \\
\text { symbolic, etc.) }\end{array}$ & $\begin{array}{l}\text { Wording of verbal } \\
\text { claims }\end{array}$ \\
\hline $\begin{array}{l}\text { Health claims by: } \\
\text { Nutrient and other function claims } \\
\text { Reduction of disease risk claims } \\
\text { General health claims }\end{array}$ & $\begin{array}{l}\text { Presence of claims for NCDs and health } \\
\text { conditions related to NCDs }\end{array}$ & $\begin{array}{l}\text { Presence of claims for other diseases and } \\
\text { health conditions } \\
\text { Format of claims (whether verbal, numerical, } \\
\text { symbolic, etc.) }\end{array}$ & $\begin{array}{l}\text { Wording of verbal } \\
\text { claims }\end{array}$ \\
\hline Other contextual information & $\begin{array}{l}\text { Food labelling legislation and voluntary } \\
\text { guidelines }\end{array}$ & & \\
\hline
\end{tabular}

*Characterizing ingredient: 'where the ingredient or category of ingredients is essential to characterize a food and to distinguish it from products with which it might be confused because of its name or appearance' (47).

†Not necessarily to be ascertained from the packaging alone for certain formats

NCD, non-communicable diseases; QUID, quantitative ingredient declaration.

healthy food choices through the provision of information and claims for foods.

In analysing food labelling data, it is, therefore, proposed that the relevant food labelling legislation and any voluntary guidelines for food labelling that are applicable in the jurisdiction where the monitoring takes place should be used. Almost all countries have some labelling legislation (10). Voluntary guidelines for some labelling components are more likely than others; for example, voluntary guidelines (produced by governments, non-governmental organisations and industry-funded bodies) for the content and format of supplementary nutrition information are now relatively common.

It is proposed that composition data for the foods that do or do not bear particular forms of labelling will also be necessary for minimal monitoring, and will be necessary, for example, for assessing whether nutrition claims are in line with Codex standards (see later). Composition data for foods is the subject of another INFORMAS module (43) and it would be sensible to collect composition data and labelling data in tandem. Price is another aspect of foods that could be used (in 'expanded' monitoring) in the analysis of food labelling data, and is the subject of an INFORMAS module (44).

Table 3 summarizes our proposed approach to monitoring health-related food labelling in relation to its content, format and context.

\section{Measurement indicators and proposed benchmarks}

Monitoring data can be evaluated between countries or regions and over time by comparing a 'suite' of measurement indicators. The indicators proposed here (Table 4) are related to global or national food labelling policy. Measurement of these indicators would provide an overview of the food labelling environment.

These indicators can be used to measure the success (or failure) of policy changes or advocacy (measured in the process modules of INFORMAS $(45,46)$ ) aimed at creating healthier food (including labelling) environments. Benchmarks for each indicator have been identified in order 
Table 4 Proposed indicators and suggested benchmarks relating to the prioritized food labelling components

\begin{tabular}{|c|c|c|}
\hline $\begin{array}{l}\text { Food labelling } \\
\text { component }\end{array}$ & Indicator & Benchmark \\
\hline $\begin{array}{l}\text { Lists of } \\
\text { ingredients }\end{array}$ & $\begin{array}{l}\text { Proportion of foods with a list of ingredients } \\
\text { Proportion of foods with QUID* }\end{array}$ & $\begin{array}{l}\text { All foods should have a list of ingredients } \\
\text { All foods should have QUID for at least all characterizing } \\
\text { ingredients }^{\dagger}\end{array}$ \\
\hline $\begin{array}{l}\text { Nutrient } \\
\text { declarations }\end{array}$ & $\begin{array}{l}\text { Proportion of foods with a nutrient declaration } \\
\text { Proportion of foods with a nutrient declaration in line with } \\
\text { Codex standards }\end{array}$ & $\begin{array}{l}\text { All foods should have a nutrient declaration } \\
\text { All foods should have a nutrient declaration in line with Codex } \\
\text { standards }\end{array}$ \\
\hline SNI & $\begin{array}{l}\text { Proportion of foods with SNIS } \\
\text { Proportion of foods with each different SNI scheme in use }\end{array}$ & $\begin{array}{l}\text { All foods should have a SNI which is at least as 'interpretive' as } \\
\text { traffic-light labelling of nutrients } \\
\text { The number of SNI schemes in use should be one }\end{array}$ \\
\hline $\begin{array}{l}\text { Nutrition } \\
\text { claims }\end{array}$ & $\begin{array}{l}\text { Proportion of foods making a claim that meets Codex } \\
\text { standards } \\
\text { Proportion of foods making a claim that are healthy }{ }^{\ddagger}\end{array}$ & $\begin{array}{l}\text { All nutrition claims should meet Codex standards }{ }^{\S} \\
\text { All nutrition claims should only be made for foods that are healthy }\end{array}$ \\
\hline $\begin{array}{l}\text { Health } \\
\text { claims }\end{array}$ & $\begin{array}{l}\text { Proportion of health claims referencing NCDs } \\
\text { Proportion of foods making a claim that are healthy }{ }^{\ddagger}\end{array}$ & $\begin{array}{l}\text { All health claims should related to important }{ }^{\ddagger} \text { health problems } \\
\text { All health claims should only be made for foods that are healthy }{ }^{\ddagger}\end{array}$ \\
\hline
\end{tabular}

*Quantitative ingredient declaration.

tSee footnote to Table 2.

‡With respect to an agreed definition or definitions.

§Benchmark derived from Codex Standards.

NCD, non-communicable diseases; QUID, quantitative ingredient declaration; SNI, supplementary nutrition information.

to enable future demonstration of which food labelling policies are working well, and allow the identification of areas where policies need to be put in place to reach those benchmarks. The benchmarks proposed are based on, but exceed, Codex standards.

Assessment of the proposed 10 simple indicators will give an easily interpretable snapshot of the impact of public and private sector actions on improving food labelling environments. While measurement of these indicators will be consistent among all participating countries, the benchmarks for each indicator may vary to account for the baseline provision of labelling and specific labelling components in that country or region. Measurement of these indicators should support efforts to improve healthrelated food labelling in participating countries.

\section{Conclusions}

This paper proposes a framework for monitoring healthrelated food labelling. This framework is aimed at facilitating the collection and analysis of country-level data on the food-labelling environment. Data from such monitoring can be used not only to monitor countries' progress towards creating healthier food environments, but also to compare progress between countries.

There are many aspects of the food labelling environment, ranging from the venues where labelling is found to the format of the labelling. This paper has focused on the monitoring of labelling on foods sold in retail outlets. However, future papers related to this module of INFORMAS could (and should) be developed to encompass the many other aspects of the food labelling environment, including labelling in other venues (e.g. restaurants, workplaces, etc.), other mediums of labelling (e.g. labelling in online supermarkets or on company websites), and ever more detailed aspects of the content, format and context of food labelling.

The monitoring of food labelling along with the other modules of INFORMAS will provide standardized assessments of the food environment, and point to areas where policies and actions are needed to make the environment more conducive to healthy food choices. Major reductions in obesity and diet-related NCDs are unlikely to occur without major improvements in the healthiness of food environments.

\section{Acknowledgements}

The authors would like to thank Anja Mizdrak and Asha Kaur for their help preparing this paper. The Rockefeller Foundation kindly supported the work of INFORMAS by hosting the first formal meeting of INFORMAS at the Rockefeller Foundation Bellagio Centre, Italy from 19 to 23 November 2012. The following organizations provided funding support for the travel of participants to Italy for this meeting and the preparation of background research papers: The Rockefeller Foundation, International Obesity Taskforce (IOTF), University of Auckland, 
Deakin University, The George Institute, University of Sydney, Queensland University of Technology, University of Oxford, University of Pennsylvania Perelman School of Medicine, World Cancer Research Fund International, University of Toronto, and The Australian National University. The authors would like to thank Francesco Branca and Godfrey Xuereb from the World Health Organization for their participation in the first formal meeting of INFORMAS, and for their input into this paper. The Faculty of Health at Deakin University kindly supported the costs for open access availability of this paper, and the Australian National Health and Medical Research Council Centre for Research Excellence in Obesity Policy and Food Systems (APP1041020) supported the coordination and finalizing of INFORMAS manuscripts.

\section{Conflicts of interest}

Bruce Neal is the Chair of the Australian Division of World Action on Salt and Health (2007-ongoing), was a Member of the Pepsico Global Scientific Advisory Board (2010-2012), was the Independent Adjudicator for the Australian Responsible Marketing to Children's Initiative (2009-2010) and holds funding from the Australian Food and Grocery Council as part of a National Health and Medical Research Council of Australia Partnership project (2010-2014). The other authors declare that they have no competing interests.

\section{References}

1. Codex Alimentarius Commission. Codex General Standard for the Labelling of Prepackaged Foods, (CODEX STAN 1-1985). 2010. Rome, Amended 1991, 1999, 2001, 2003, 2005, 2008 and 2010.

2. Cowburn G, Stockley L. Consumer understanding and use of nutrition labelling: a systematic review. Public Health Nutr 2005; 8: 21-28.

3. Mhurchu CN, Gorton D. Nutrition labels and claims in New Zealand and Australia: a review of use and understanding. Aust $\mathrm{N}$ Z J Public Health 2007; 31: 105-112.

4. Campos S, Doxey J, Hammond D. Nutrition labels on prepackaged foods: a systematic review. Public Health Nutr 2011; 14: 1496-1506.

5. Institute of Medicine Committee on Examination of Frontof-Package Nutrition Rating Systems and Symbols (Phase II). Front-of-package nutrition rating systems and symbols. Institute of Medicine: Washington, D.C., 2011.

6. Hieke S, Taylor CR. A critical review of the literature on nutritional labeling. J Consum Aff 2012; 46: 120-156.

7. Hawley KL, Roberto CA, Bragg MA, Liu PJ, Schwartz MB, Brownell KD. The science on front-of-package food labels. Public Health Nutr 2013; 16: 430-439.

8. Hersey JC, Wohlgenant KC, Arsenault JE, Kosa KM, Muth MK. Effects of front-of-package and shelf nutrition labeling systems on consumers. Nutr Rev 2013; 71: 1-14.
9. Grunert KG, Wills JM. A review of European research on consumer response to nutrition information on food labels. J Public Health 2007; 15: 385-399.

10. World Health Organization. Nutrition labels and health claims: the global regulatory environment: Geneva, 2004.

11. Codex Alimentarius Commission. Guidelines on Nutrition Labelling (CAC/GL 2-1985). 2012. Rome, Adopted 1985, revised 1993 and 2011, amended 2003, 2006, 2009, 2010, 2012, annex adopted 2011.

12. Codex Alimentarius Commission. Guidelines for use of Nutrition and Health Claims (CAC/GL 23-1997). 2012. Rome, Adopted in 1997, revised in 2004, amended in 2001, 2008, 2009, 2010, 2011 and 2012, annex adopted 2009.

13. Hawkes C. Government and voluntary policies on nutrition labelling: a global overview. In: Albert J (ed.). Innovations in food Labelling, Woodhead Food Series no. 184. Woodhead Publishing Ltd: Cambridge, 2010, pp. 37-58.

14. Swinburn B, Sacks G, Vandevijvere $S$ et al. International Network for Food and Obesity/non-communicable diseases Research, Monitoring and Action Support (INFORMAS): overview and key principles. Obes Rev 2013; 14 (Suppl. 1): 1-12. 15. L'Abbe M, Schermel A, Minaker L et al. Monitoring foods and beverages provided and sold in public sector settings. Obes Rev 2013; 14 (Suppl. 1): 96-107.

16. Cammans J. Nutrition, health \& related claims: pilot survey of nutrition, health and related claims in South Australia. South Australia Department of Health, 2006.

17. Caswell JA. Current information levels on food labels. Am J Agric Econ 1992; 74: 1196-1201.

18. Caswell JA, Ning YM, Liu F, Mojduszka EM. The impact of new labeling regulations on the use of voluntary nutrient-content and health claims by food manufacturers. J Public Policy Mark 2003; 22: 147-158.

19. Colby SE, Johnson L, Scheett A, Hoverson B. Nutrition marketing on food labels. J Nutr Educ Behav 2010; 42: 92-98.

20. Lalor F, Kennedy J, Flynn MA, Wall PG. A study of nutrition and health claims - a snapshot of what's on the Irish market. Public Health Nutr 2010; 13: 704-711.

21. Lv J, Chen Y, Wang S et al. A survey of nutrition labels and fats, sugars, and sodium ingredients in commercial packaged foods in Hangzhou, China. Public Health Rep 2011; 126: 116-122.

22. Mayer JA, Maciel TL, Orlaski PL, Flynn-Polan G. Misleading nutrition claims on cracker packages prior to and following implementation of the Nutrition Labeling and Education Act of 1990. Am J Prev Med 1998; 14: 189-195.

23. Ricciuto L, Tarasuk V. The relationship between price, amounts of saturated and trans fats, and nutrient content claims on margarines and oils. Can J Diet Pract Res 2005; 66: 252-255.

24. Walker KZ, Woods J, Ross J, Hechtman R. Yoghurt and dairy snacks presented for sale to an Australian consumer: are they becoming less healthy? Public Health Nutr 2010; 13: 1036-1041. 25. Wang S, Chen Y, Liu M et al. The changes of nutrition labeling of packaged food in Hangzhou in China during 2008 2010. PLOS ONE 2011; 6: e28443.

26. Washi S. Nutritional aspects of food labeling in Saudi Arabia. Ahfad J 2001; 18: 17-29.

27. Williams P, Duncan R, Agnoli KD, Hull A, Owers A. Front of pack daily intake labelling on Australian packaged foods: introduction and use 2007-2009. Food Aust 2010; 62: 583-588. 28. Williams P, Yeatman H, Ridges L et al. Nutrition function, health and related claims on packaged Australian food products prevalence and compliance with regulations. Asia Pac J Clin Nutr 2006; 15: 10-20. 
29. Williams P, Yeatman H, Zakrzewski S et al. Nutrition and related claims used on packaged Australian foods - implications for regulation. Asia Pac J Clin Nutr 2003; 12: 138-150.

30. Woods J, Walker K. Choosing breakfast: how well does packet information on Australian breakfast cereals, bars and drinks reflect recommendations? Nutr Diet 2007; 64: 226-233.

31. Brandt M, Moss J, Ferguson M. The 2006-2007 Food Label and Package Survey (FLAPS): nutrition labeling, trans fat labeling. J Food Compost Anal 2009; 22: S74-S77.

32. Brecher SJ, Bender MM, Wilkening VL, McCabe NM, Anderson EM. Status of nutrition labeling, health claims, and nutrient content claims for processed foods: 1997 Food Label and Package Survey. J Am Diet Assoc 2000; 100: 1057-1062.

33. Goglia R, Spiteri M, Menard C et al. Nutritional quality and labelling of ready-to-eat breakfast cereals: the contribution of the French observatory of food quality. Eur J Clin Nutr 2010; 64: S20-S25.

34. Legault L, Brandt MB, McCabe N, Adler C, Brown AM, Brecher S. 2000-2001 food label and package survey: an update on prevalence of nutrition labeling and claims on processed, packaged foods. J Am Diet Assoc 2004; 104: 952-958.

35. Menard C, Dumas C, Gillot N et al. The French OQALI survey on dairy products: comparison of nutrient contents and other nutrition information on labels among types of brands. J Hum Nutr Diet 2012; 25: 323-333.

36. Schwartz MB, Vartanian LR, Wharton CM, Brownell KD. Examining the nutritional quality of breakfast cereals marketed to children. J Am Diet Assoc 2008; 108: 702-705.

37. AsureQuality Australia Pty Ltd. Ongoing Food Label Monitoring Survey in Australia and New Zealand: report on the assessment of 2005 labels for key mandatory labelling elements for consistency against labelling provisions (phase 2 report): Canberra, 2008.

38. Storcksdieck Genannt Bonsmann S, Celemin LF, Larranaga A et al. Penetration of nutrition information on food labels across the EU-27 plus Turkey. Eur J Clin Nutr 2010; 64: 1379-1385.

39. Trichterborn J, Harzer G, Kunz C. Fine bakery wares with label claims in Europe and their categorisation by nutrient profiling models. Eur J Clin Nutr 2011; 65: 307-312.

40. Trichterborn J, Harzer G, Kunz C. Nutrient profiling and food label claims: evaluation of dairy products in three major European countries. Eur J Clin Nutr 2011; 65: 1032-1038.

41. Food Standards Agency. Audit of the range of health claims made for foods on the UK market in September 2003, 2003.

42. Joint WHO/FAO Expert Consultation. Diet, Nutrition and the Prevention of Chronic Diseases. World Health Organization: Geneva, 2003.

43. Neal B, Sacks G, Swinburn B et al. Monitoring the levels of important nutrients in the food supply. Obes Rev 2013; 14 (Suppl. 1): 49-58.

44. Lee A, Ni Mhurchu C, Sacks G et al. Monitoring the price and affordability of foods and diets globally. Obes Rev 2013; 14 (Suppl. 1): 82-95.

45. Sacks G, Swinburn B, Kraak VI et al. A proposed approach to assessing the extent to which the policies and actions of private sector organisations affect food environments and influence obesity/non-communicable diseases prevention efforts. Obes Rev 2013; 14 (Suppl. 1): 38-48.

46. Swinburn B, Vandevijvere S, Kraak VI et al. The government healthy food environment policy index for monitoring and benchmarking government policies and actions to improve the healthiness of food environments. Obes Rev 2013; 14 (Suppl. 1): 24-37.

47. European Union. EU Regulation no. 1169/2011 on the provision of food information to consumers. Brussels, 2011.

\section{Glossary}

\section{Definitions from Codex standards and guidelines}

Food labelling - 'any written, printed or graphic matter is present on the label, accompanies the food, or is displayed near the food, including that for the purpose of promoting its sale or disposal.' (STAN 1-1985)

List of ingredients - 'All ingredients [in a food] shall be listed in descending order of ingoing weight $\left(\mathrm{m} \mathrm{m}^{-1}\right)$ at the time of the manufacture of the food.' (STAN 1-1985)

Nutrition labelling - 'a description intended to inform the consumer of nutritional properties of a food.' (CAC/GL 2-1985)

Nutrient declaration - nutrition labelling which is 'a standardized statement or listing of the nutrient content of a food.' (CAC/GL 2-1985)

Supplementary nutrition information - nutrition labelling 'intended to increase the consumer's understanding of the nutritional value of their food and to assist in interpreting the nutrient declaration.' (CAC/GL 2-1985)

Nutrition claim - 'any representation which states, suggests or implies that a food has particular nutritional properties including but not limited to the energy value and to the content of protein, fat and carbohydrates, as well as the content of vitamins and minerals.' (CAC/GL 23-1997)

Nutrient content claim - 'a nutrition claim that describes the level of a nutrient contained in a food [or its energy value]' (CAC/GL 23-1997). [In this taxonomy nutrient content claims include 'Non-addition claims' defined by CAC/GL 23-1997 as 'any claim that a [nutrient] has not been added to a food, either directly or indirectly. The [nutrient] is one whose presence or addition is permitted in the food and which consumers would normally expect to find in the food']

Nutrient comparative claim - 'a [nutrition] claim that compares the nutrient levels and/or energy value of two or more foods.' (CAC/GL 23-1997)

Health claim - 'any representation that states, suggests, or implies that a relationship exists between a food or a constituent of that food and health.' (CAC/GL 23-1997)

Nutrient function claim - 'a [health] claim that describes the physiological role of the nutrient in growth, development and functions of the body.' (CAC/GL 23-1997) [Although Codex classifies nutrient function claims as nutrition claims it seems more logical to classify them as health claims]

Other function claim - health 'claims concerning specific beneficial effects of the consumption of foods or their constituents, in the context of the total diet on normal functions or biological activities of the body. Such claims relate to a positive contribution to health or to the improvement of a function or to modifying or preserving health.' (CAC/GL 23-1997) 
Reduction of disease risk claim - health 'claims relating the consumption of a food or food constituent, in the context of the total diet, to the reduced risk of developing a disease or health-related condition.' (CAC/GL 23-1997)

\section{Definitions for the purpose of this INFORMAS module}

Health-related ingredient claim - any representation which states, suggests or implies that a food has particular nutritional properties not related to its energy value or to the content of protein, fat and carbohydrates, vitamins and minerals but related to the content of an ingredient'

General health claim - a health claim concerning the general beneficial effects of the consumption of foods or their constituents on health.

[NB Codex (CAC/GL 23-1997) does have a category of permitted claim called 'Claims related to dietary guidelines or healthy diets' which is similar to our category general health claim but specifies that 'Foods should not be described as "healthy" or be represented in a manner that implies that a food in and of itself will impart health', whereas our category of general health claim would include claims such as 'healthy'.]

\section{Definitions of sub-components of 'supplementary nutrition information' adapted from those of the Institute of Medicine (IOM, 2011)}

Nutrient specific systems - supplementary nutrition information which displays the amount of select nutrients from the nutrient declaration using numbers including \% Daily Values ( $\% \mathrm{DV}$ ) or \% Guideline Daily Amounts (\%GDA) or words such as 'high,' 'medium,' or 'low' or traffic-light colours or symbols, etc.

Summary indicator systems - supplementary nutrition information which use a single symbol, icon, or score to provide summary information about the nutrient content of a product. Products are given a numeric score (i.e. 1-100) or number of symbols (e.g. $0,1,2,3$ ) to indicate the nutritional quality of the product. (NB Summary indicator systems do not include symbolic representations of the verbal claim 'healthy', e.g. the Nordic Keyhole)

(Note that the Institute of Medicine has a third type of Supplementary nutrition information called Food group information systems - defined as supplementary nutrition information that uses a symbol awarded to a product based on the presence of a certain food group or ingredient, but in our taxonomy such labelling is classified as a claim because products without the food group or ingredient are not labelled unlike the other two types of supplementary nutrition information).

\section{Bibliography for this glossary}

Codex Alimentarius Commission. Codex General Standard for the Labelling of Prepackaged Foods, CODEX STAN 1-1985, Rev.1991, 2001, 2010. Food and Agriculture Organization of the United Nations/World Health Organization, Rome.

Codex Alimentarius Commission. Guidelines on Nutrition Labelling, CAC/GL 2-1985. Revisions 1993 and 2011. Amendment 2003, 2006, 2009, 2010 and 2012. Annex adopted 2011. Food and Agriculture Organization of the United Nations/World Health Organization, Rome.

Codex Alimentarius Commission. Guidelines For Use of Nutrition and Health Claims, CAC/GL 23-1997. Revised in 2004. Amended in 2001, 2008, 2009, 2010, 2011 and 2012. Annex adopted 2009 Food and Agriculture Organization of the United Nations/World Health Organization, Rome.

Institute of Medicine Committee on Examination of Front-of-Package Nutrition Rating Systems and Symbols (Phase II), Front-of-Package Nutrition Rating Systems and Symbols. IOM, Washington, D.C. 2011. 